Berg, P., and Reed D. (2019). "Capability-Building Competition in Construction: Case Study Reinterpretation." In: Proc. 27th Annual Conference of the International. Group for Lean Construction (IGLC), Pasquire C. and Hamzeh F.R. (ed.), Dublin, Ireland, pp. 265-274. DOI: https://doi.org/10.24928/2019/0219. Available at: 〈www.iglc.net>.

\title{
CAPABILITY-BUILDING COMPETITION IN CONSTRUCTION: CASE STUDY REINTERPRETATION
}

\author{
Peter Berg ${ }^{1}$, and Dean Reed ${ }^{2}$
}

\begin{abstract}
This industry paper is applied research with the purpose of answering whether Takahiro Fujimoto's theory of capability-building competition in the automobile industry can be applied to the construction industry. This study begins with an empirical account of the work a series of project teams did to prefabricate and install exterior wall (X-wall) panels on six different buildings. The authors then explain relevant aspects of Fujimoto theory. Finally, the authors create a framework for evaluating the work in light of this theory and do so. The authors find that Fujimoto's theory is relevant to construction. This paper is limited because the construction data set is relatively small and the evaluation of the competitiveness of routines and learning is based on the assessment of the first author, who initiated and directly managed the work on two projects and was engaged in its development on later projects. The paper is relevant for industry professionals because Lean management and process capability is required to make value flow to customers. Lean Construction theory can advance by understanding the elements of capability-building in the auto industry and how they can be applied to design and construction.
\end{abstract}

\section{KEYWORDS}

Theory, transformation, flexible manufacturing, evolutionary, emergence

\section{INTRODUCTION}

The authors observation, based on many years of practice, is that the construction industry lacks a language, and therefore theory to methodically improve and develop new capability that would provide greater value. This paper seeks to address the question of whether Takahiro Fujimoto's theory of capability-building competition in the automobile industry can be applied to construction, in contrast to placing Fujimoto in a system view of Lean Construction (Picchi 2001). The method is to describe capability-building on a series of building projects, then introduce and use Fujimoto's theory to reinterpret the development of onsite pre-fabrication and assembly of exterior wall (X-wall) panels on a series of buildings.

Project Executive, DPR Construction, 222 N. 44th Street, Phoenix, AZ 85034, USA, peterb@dpr.com

Lean/Integration Advocate, DPR Construction, 1450 Veterans Boulevard, Redwood City, CA 94063,

USA, deanr@dpr.com 


\section{CASE STUDY: EXTERIOR WALL PRE-FABRICATION}

\section{THE HSEB EXPERIMENT: THE IDEA \& TEAM BUY-IN}

Traditional exterior building wall (X-wall) installation involves "stick building", or installing individual metal studs atop scaffold, then applying gypsum sheathing, water vapor barrier, z-girts, insulation, hat channel and finally copper rain screen. Working atop scaffold is very dangerous due to possible collapse, falling objects and cramped work space; it is also difficult for craftspeople to install work around bracing. Site and exterior wall work, that could otherwise progress, cannot be completed until scaffold is removed. And finally, scaffold is a temporary structure that is removed from the project, adding little value while costing a great amount in terms of safety, quality and money.

In 2010, the General Contractor Project Executive (PX) working on a new 6-story 270,000 square foot medical school building asked his project team if there was a way to install X-wall without scaffold by prefabricating modules on the ground and hoisting them onto the building. The project team responded by noting a number of barriers that would make installation without scaffold very difficult, if not impossible. After a back and forth discussion and no progress, the PX asked the team if trying a pre-fabrication approach on a single elevation would help by minimizing the risk that failed implementation would adversely impact the project. ${ }^{3}$ The PX also committed to the team that he would accept sole responsibility and any resulting consequences for failure on behalf of the team. The team deliberated, then agreed that attempting pre-fabrication for the first time on a single elevation was a tolerable level of risk and committed to the approach. The North X-wall elevation was selected because of its geometric simplicity compared to the other elevations; it was essentially a vertically flat plane from a panel perspective.

\section{Designing The Process}

Once the team committed, they had to learn what information, resources and steps were required to complete the North elevation using pre-fabrication. They started by mapping the work: create fabrication drawings; build the fabrication shop; order materials; create the fabrication schedule; fabricate and install panels. As the team thought about and pursued each step, they encountered many questions, problems and things that were not initially anticipated. Each step represented a new capability that the team had never performed before.

Fabrication drawings were typically not produced for walls framed in place (stick-built) built standing on a scaffold, so the team had to create a process to design them. Prefabricating panels required the project team to understand 3-dimensional tolerance variations across the complete north elevation; if the slab edge was inside or outside of the designed location they needed to know in advance because that would cause the panel structural connection and wall to be in the incorrect location. Additionally, if the slab edge was low or high, panels would be located incorrectly for the same reason. Once existing tolerances were understood, a flexible panel attachment could be designed to compensate

${ }^{3}$ Arguments for and against X-Wall Pre-fabrication are listed in Table 4 in the Appendix, available on request to the authors. 
for out-of-tolerance existing conditions. The team blended laser-scanning technology with surveying and 3-D drafting to develop an as-built scanning process to deliver accurate useful information that could be incorporated into the fabrication drawings and overlaid onto the 3-D building design model, enabling flexible panel attachment design. Fabrication drawing capability necessitated as-built scanning capability.

\section{FABRICATION SHOP}

Off-site and on-site panel fabrication shop locations were analyzed. With all factors included: cost, schedule, site logistics, transportation, accessibility, rigging, hoisting, work environment, quality installation, inspections, and not having an existing fabrication space, the team decided to move forward with constructing the panels onsite. Shop size was determined by calculating the panel production rate required by the project schedule. The team concluded all panels could be fabricated at the needed production rate on two field fabricated jig tables utilizing minimal space. A multi-trade step-by-step workflow was mapped out by the workers. A pull production schedule was developed to support the project schedule, materials were ordered and delivered on a weekly basis to support production, and fabrication commenced.

\section{RigGing, Hoisting AND INSTALlation}

Rigging and hoisting each of the panels was a concern. Walls are traditionally designed for static vertical loads; pre-fabrication requires rigging and hoisting the panels, which imposes $\mathrm{x}, \mathrm{y}$ and $\mathrm{z}$ dimensional dynamic loads on the panels. Analysis by the team and cold-form steel engineer concluded that cold-formed steel cross braces fastened to the interior side of the $\mathrm{X}$-wall were required to prevent possible wall frame deflection during the hoisting process. Two removable rigging eyelet connections were designed and installed at the top and at a location at either end of each panel prescribed by the structural engineer. Prior to hoisting, installers marked the precise locations of each panel to be hoisted on the top, vertical edge and bottom of the concrete slab. One half of the flexible $\mathrm{X}$-wall panel structural connection was welded to a steel plate embedded into the concrete slab edge in the exact location needed to receive the panel side of the structural connection. All field dimensions were located using information from the 3-dimensional fabrication model uploaded into laser-based surveying equipment. This combination of conventional field markings, pre-installed structural connection and model-based laser surveying insured that each panel was installed and located without error. With all safety and quality measures in place, the panels were then hoisted into their respective locations on the building and permanently connected.

\section{Scaling / Paying It Forward}

The team diligently documented everything involved in this experiment of pre-fabricating a single elevation. Workers for the GC from other projects were invited at multiple points to visit the project for purposes of sharing experiences. Future projects decided to use this pre-fabrication approach due to its benefits. Each future project made improvements to the initial approach, one experience building upon another. These projects are described in Table 5 of the Appendix, available on request to the authors. 


\section{THEORY OF CAPABILITY-BUILDING COMPETION}

In the book, The Evolution of a Manufacturing System at Toyota, Takahiro Fujimoto attempted to fill in three missing pieces in the story of how a total manufacturing system evolves: the evolutionary perspective for detailed analysis of manufacturing; the information approach to manufacturing routines at the total system level; and the threelayer framework of organizational capabilities: routinized manufacturing, routinized learning, and evolutionary learning.

The evolutionary view is the idea that systems evolve because of unanticipated events and unplanned behavior and is related to system emergence. Fujimoto uses the term "multipath system emergence" to describe an interplay of both intended and unintended consequences for the people who create a system, when decision-makers don't often know beforehand which path will lead to a successful outcome: deliberate planning, environmental imperatives, intuition, imitation or luck. Emergence means that a certain system trait cannot be explained by the behavior of its constituent parts alone or predicted from the previous states of the system owing to its complexity from the observer's point of view. Fujimoto describes the three levels (or "layers") of organizational capabilities in Table 1.

Table 1: Three Levels of Manufacturing Capability (Takahiro Fujimoto 1999)

\begin{tabular}{cccc}
\hline Capability Level & Basic Nature & Influence & Characteristics \\
\hline $\begin{array}{c}\text { 1. Routinized } \\
\text { manufacturing } \\
\text { capability }\end{array}$ & Static \& routine & $\begin{array}{c}\text { Competitive } \\
\text { performance in } \\
\text { stable environment }\end{array}$ & $\begin{array}{c}\text { Firm-specific pattern of a } \\
\text { steady-state information } \\
\text { system in terms of efficiency } \\
\text { and accuracy of repetitive } \\
\text { information transmission }\end{array}$ \\
$\begin{array}{c}\text { 2. Routinized } \\
\text { learning }\end{array}$ & $\begin{array}{c}\text { Dynamic \& } \\
\text { routine }\end{array}$ & $\begin{array}{c}\text { Changes or } \\
\text { recoveries of } \\
\text { competitive } \\
\text { performance }\end{array}$ & $\begin{array}{c}\text { Firm-specific ability of } \\
\text { handling repetitive problem- } \\
\text { solving cycles or a routinized } \\
\text { pattern of system changes }\end{array}$ \\
$\begin{array}{c}\text { 3. Evolutionary } \\
\text { learning }\end{array}$ & $\begin{array}{c}\text { Dynamic \& non- } \\
\text { routine }\end{array}$ & $\begin{array}{c}\text { Changes in patterns } \\
\text { of routine capability }\end{array}$ & $\begin{array}{c}\text { Firm-specific ability of } \\
\text { handling system emergence } \\
\text { or non-routine patterns of } \\
\text { system changes in building } \\
\text { routine capabilities }\end{array}$ \\
\hline
\end{tabular}

The third level of the framework is evolutionary learning capability, which is also dynamic but differs from routinized learning capability because it is related to higher order system changes that are irregular and infrequent, and are often connected with rare, episodic and unique historical events. Evolutionary learners do not even know in advance if this route is open to them. Evolutionary learning capability is a firm-specific ability to cope with a complex historical process of capability-building, multi-path system emergence, that is neither totally controllable nor predictable. Fujimoto asserts that evolutionary learners simultaneously activate two different modes of learning: intentional and opportunistic. 
Figure 1 shows Fujimoto's operational definition of multi-path system development and evolutionary learning capability.

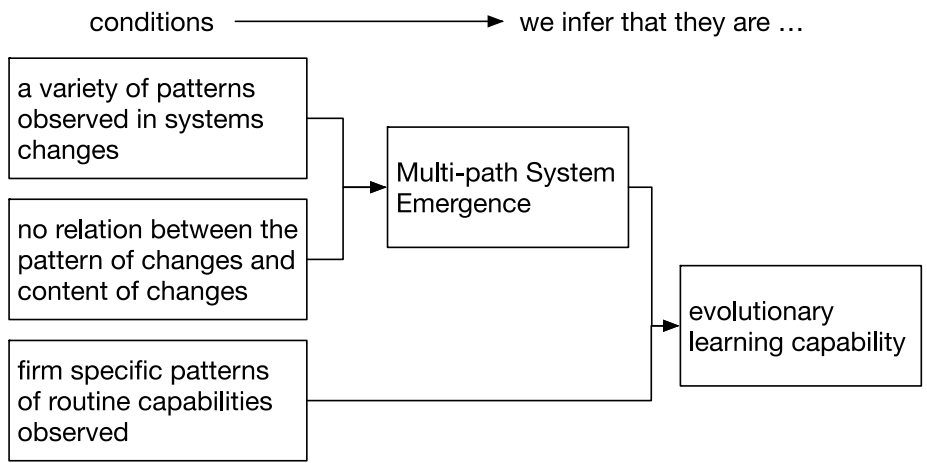

Figure 1: Operational Definitions of Multi-path System Emergence \& Evolutionary Learning Capability (Takahiro Fujimoto 1999)

Fujimoto propose a dual-layer (or "level") problem-solving framework to explain the evolutionary process of system emergence, one that consists of two levels of partial or incomplete problem-solving processes, shown in Figure 2. The lower level mechanism, representing the process of system emergence generates miscellaneous solutions for various purposes, while the upper level mechanism, reflecting a certain evolutionary learning capability of the firm, absorbs the solutions and converts them to manufacturing capabilities.

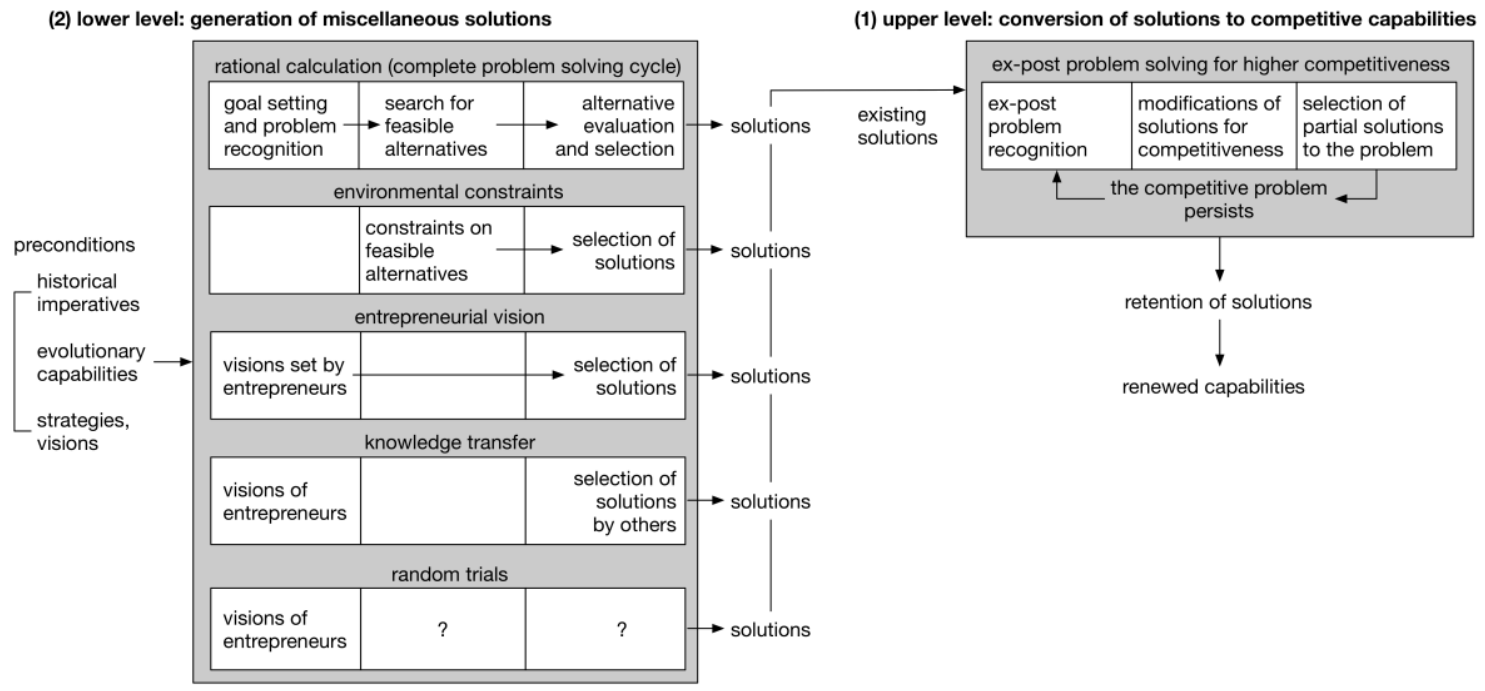

Figure 2: Dual-Layer Problem-Solving (Takahiro Fujimoto 1999)

Fujimoto believes that focusing on information offers the only way to understand the total system because it runs through the three basic components of Toyota's system: production, product development and supplier systems, and carries value beyond the boundaries of manufacturing, circulating between the producer (including its suppliers), and customer. 
Fujimoto asserts that the basic unit of an information system is a combination of information and its medium - an information asset and information processing as activities that change the state of an information asset, including information content, medium, and location. Fujimoto's definition of information processing includes "not only what computers and telecommunication devices do but also human communication, knowledge creation, and even physical transformation." In addition to multi-path system emergence, Fujimoto postulates that problem-solving cycles also explain information system changes. "A problem-solving cycle refers to a series of information processing in which goals or problems (i.e., input information) are converted to solutions to the problems (i.e., output information), using regular heuristics ..." A typical cycle includes five steps (goal setting, alternative idea generation, model development, experiment, and selection) and is typically initiated by recognition of certain problems (i.e., gaps between goals and current situations). "Alternative ideas are then created or retrieved from the repertoire. Since knowledge of the causal relationship between the alternatives and their consequences is normally imperfect, the cycle typically develops simulation models and conducts experiments for various possible combinations. After the results are evaluated, an acceptable alternative may be selected or a new cycle of problem-solving may begin. As a result of a problem-solving cycle, the solution set (i.e., information content) of the firm changes."

Fujimoto explains that as "product development and production processes go on, the information becomes refined from product concepts to basic or functional product designs, finalized as detailed (structural) product designs, translated and deployed in production processes, and eventually transmitted to the products." Fujimoto argues that "production activity can also be regarded as transfers of the product design information from the production process to the product. At each station of the process, a fraction of the product design information - stored in the workers, tools, equipment, manuals, and so on - is transferred to material or work in process, which 'absorbs' the information step by step and is transformed eventually to a product." Figure 3 shows the relationship between multipath system emergence, evolutionary learning capability, information routines for learning and manufacturing, and manufacturing performance.

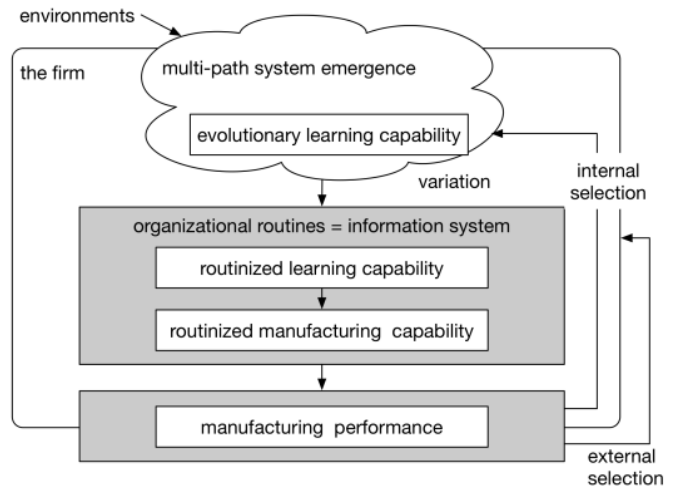

Figure 3: System Emergence and Information Routines (Takahiro Fujimoto 1999)

Fujimoto notes that the "Toyota-style production system focuses on reduction of "muda," or the time when information transmission is not happening (i.e., non-transmission time) on both the sender and receiver side." For example, in "a labor-intensive process, trained 
workers are the senders and works-in-process are the receivers of the value-carrying information. The system aims at low levels of non-value-adding time on the worker side (e.g., waiting time) on the one hand, and non-value-receiving time on the work-in-process side (e.g., inventory) on the other."

Fujimoto explains that once transmission errors happen, they have to be detected and proper remedies have to be implemented. "Effective automakers tend to reduce the lead time between fabrication and inspection, and thereby make information feedback cycles quick. On-the-spot inspection, in which direct workers (including team leaders) inspect what they just made before transferring it to the downstream step, is a typical example."

Continuous improvement of productivity and quality (kaizen) is often seen as a core capability of effective Japanese production systems. Fujimoto asserts that "the idea of a factory as a 'learning laboratory' applies here. The elements of both just-in-time and total quality control appear to contribute jointly to a Toyota-style capability of routinized learning (i.e., repetitive problem-solving) ..."

Fujimoto states that "the functional principle behind effective manufacturing routines is quite simple and straightforward. The structure of the manufacturing routines may be quite entangled, but their ultimate function is almost always clear - to outperform rivals in attracting and satisfying customers. Once this principle is explicitly or intuitively understood, it is not difficult to explain the competitive function or dysfunction of an existing manufacturing routine. No matter how remote the routine-holding units are from the customer interface, they are connected to customers by the information web. No matter how remote two organizational units are (e.g., a stamping shop and a dealer's showroom), they share one informational node - the customer. And all the information held by effective routines eventually flows into this node, like all the little streams that eventually join the river."

Fujimoto explains that "the concept of 'customer orientation by all employees' is crucial - not only because it is good for customers, but also because it maintains the overall integrity of manufacturing routines. Even though Toyota's employees may never call their practices an information system, they are virtually and intuitively referring to the informational nature of their system's routine capabilities when they emphasize customers (ultimate note of information), "muda" (non-information-processing state), "the downstream station is the customer" (accurate transmission of information to the next step), and so on." Fujimoto proposes that the information network is the deep structure that governs Toyota's manufacturing activities.

Fujimoto states that "Toyota-style manufacturing routines, as a total system, are complex in the sense that they were not created by any prior grand design. However, the system is also simple in the sense that the ultimate function of individual routines can be clearly explained by a simple principle of customer satisfaction, whether they were created to achieve this intentionally or unintentionally." Fujimoto asserts "this is why companies like Toyota, which have applied such a principle throughout the firm, could consistently outperform others by cumulatively building routines that turn out to create high performances through a combination of system emergence and evolutionary capability; for such companies, the system of manufacturing routines is too complex to design ex-ante, but simple enough to grasp ex-post." (Takahiro Fujimoto 1999) 


\section{CASE STUDY REINTERPRETATION}

\section{ASSESSMENT FrAMEWORK}

Reinterpretation required designing a framework based on Fujimoto's theory for assessing the competitiveness of routines, multi-path system emergence and evolutionary learning capability within project teams for six consecutive projects.

- Assessment: the first author of this paper served as the Project Executive for the first, third and fourth projects listed in Tables 2 and 3 below, and acted as entrepreneur, process designer and teacher / mentor. He was entirely accountable for project team performance on these projects and assisted with the others. This made him the best single source for identifying routines and assessing multi-path emergence and evolutionary learning in the absence of well-defined criteria.

- Routines: ten routines, listed in Table 2, were identified for the projects.

- Competitiveness: a 0 to 5 scale was chosen to assess the impact of routines on safety, quality, schedule and cost, with each contributing a maximum of $25 \%$ towards X-wall competitiveness compared to framing and sheathing wall panels in place. The total score expressed as a percentage had no top-end limit. It was and is possible to fail to improve competitiveness or succeed beyond $100 \%$ as can be seen in Table 2 .

- Multi-Path System Emergence: a yes/no answer was given for the presence of the five paths identified by Fujimoto shown in Figure 3 above and in Table 3 below. This determined the percentage for each path's contribution to generating solutions on all six projects.

- Firm Specific Patterns of Routine Capabilities: a 0 to 5 scale was chosen to assess the degree to which ten routines, had been implemented ("routinization"). This allowed a percentage score to be calculated for each project.

- Evolutionary Learning Capability: a yes/no answer was given to assess the contribution each routine made to the $\mathrm{X}$-wall production system on each project. As with patterns of routine capabilities, a percentage score was calculated for each project. Table 3 shows these scores.

Table 2 shows the first author's assessment of the competitiveness of the routines impact on safety, quality, schedule and cost compared to framing and sheathing exterior walls in place, with each factor contributing from zero to a maximum of $25 \%$ to the cumulative score. Tables 6, 7, 8, 9, 10 and 11 in the Appendix, available on request to the authors, display the contribution each of the categories made to the project scores. ${ }^{4}$

Given the newness of the evaluation framework and the lack of criteria for evaluating the effectiveness of new routines, trends rather than absolute numbers offer the best opportunity for insight. The following trends can be seen.

Table 3 shows the first author's assessment of multi-path development, firm specific patterns of routine capabilities and evolutionary learning capability, and their contribution

\footnotetext{
${ }^{4}$ The projects are described Table 5 in the Appendix, available on request to the authors.
} 
to capability of the $\mathrm{X}$-wall production system. Tables $12,13,14,15,16$ and 17 in the Appendix, available on request to the authors, show the detailed analysis.

Table 2: Competitiveness of Routines

\begin{tabular}{cccccccc}
\hline ID & Project & $\mathbf{1}$ & $\mathbf{2}$ & $\mathbf{3}$ & $\mathbf{4}$ & $\mathbf{5}$ & $\mathbf{6}$ \\
\multicolumn{1}{c}{ Routines \& Improvement in Competitiveness } \\
\hline 1 & As-Built Scanning & $10 \%$ & $20 \%$ & $20 \%$ & $20 \%$ & $30 \%$ & $30 \%$ \\
2 & Fabrication Drawings & $10 \%$ & $20 \%$ & $20 \%$ & $20 \%$ & $30 \%$ & $40 \%$ \\
3 & Fab Shop & $15 \%$ & $15 \%$ & $15 \%$ & $25 \%$ & $30 \%$ & $30 \%$ \\
4 & Pull Production Schedule & $10 \%$ & $20 \%$ & $20 \%$ & $20 \%$ & $25 \%$ & $30 \%$ \\
5 & Panel Production & $15 \%$ & $35 \%$ & $70 \%$ & $70 \%$ & $50 \%$ & $70 \%$ \\
6 & Quality at the Source & $0 \%$ & $0 \%$ & $0 \%$ & $0 \%$ & $40 \%$ & $15 \%$ \\
7 & Rigging \& Hoisting & $5 \%$ & $10 \%$ & $10 \%$ & $20 \%$ & $40 \%$ & $40 \%$ \\
8 & Install & $10 \%$ & $20 \%$ & $20 \%$ & $20 \%$ & $40 \%$ & $60 \%$ \\
9 & Pre-Pour Scan & $0 \%$ & $0 \%$ & $0 \%$ & $0 \%$ & $15 \%$ & $0 \%$ \\
10 & Post Pour Scan & $0 \%$ & $0 \%$ & $0 \%$ & $20 \%$ & $40 \%$ & $15 \%$ \\
& Improvement in Project & $75 \%$ & $140 \%$ & $175 \%$ & $215 \%$ & $340 \%$ & $330 \%$ \\
\hline & Competitiveness & & & & & & \\
\hline
\end{tabular}

Table 3: Multi-path System Emergence \& Evolutionary Learning Capability ${ }^{5}$

\begin{tabular}{cccccccc}
\hline Project & P-S & EC & EV & KT & RT & PRC & ELC \\
\hline 1 & $90 \%$ & $20 \%$ & $30 \%$ & $0 \%$ & $10 \%$ & $0 \%$ & $0 \%$ \\
2 & $70 \%$ & $10 \%$ & $0 \%$ & $70 \%$ & $0 \%$ & $14 \%$ & $10 \%$ \\
3 & $70 \%$ & $10 \%$ & $10 \%$ & $70 \%$ & $0 \%$ & $28 \%$ & $30 \%$ \\
4 & $80 \%$ & $20 \%$ & $20 \%$ & $80 \%$ & $0 \%$ & $46 \%$ & $20 \%$ \\
5 & $100 \%$ & $20 \%$ & $30 \%$ & $80 \%$ & $20 \%$ & $64 \%$ & $90 \%$ \\
6 & $90 \%$ & $20 \%$ & $20 \%$ & $80 \%$ & $20 \%$ & $84 \%$ & $80 \%$ \\
\hline
\end{tabular}

\section{Reinterpretation of X-Wall Production}

All of routines were either focused on creating or using accurate information for production to meet the end and intermediate customer's requirements. All of the project teams used

${ }^{5}$ Paths are abbreviated as follows: P-S for Problem-Solving; EC for Environmental Constraints; EV for Entrepreneurial Vision; KT for Knowledge Transfer; and RT for Random Trials. PRC stands for Firm Specific Patterns of Routine Capabilities, and ELC for Evolutionary Learning Capability. 
the Last Planner System and Building Information Modelling in pursuit of project objectives for safety, quality and elimination of waste and increased production flow.

Given the newness of the evaluation framework and the lack of criteria for evaluating the effectiveness of new routines, trends rather than absolute numbers offer the best opportunity for insight. The following trends can be seen.

- Competitiveness: the increase on the first project is a strong argument for taking the risk of doing something different, even when it is not clearly understood at the outset. The progressive and dramatic increase across all projects is an extremely good return on investment resulting from persistence. ${ }^{6}$

- Multi-Path System Emergence: knowledge and information came primarily from problem-solving throughout all projects. Site logistics constrained possible solutions on almost all of the projects. The first author proposed new approaches when his project teams could not see a path forward, the "entrepreneurial vision" Fujimoto describes. Knowledge was transferred to each successive project.

- Firm Specific Patterns of Routine Capabilities: starting from zero on HSEB, routines for gathering and using information in production became more effective and the advantages of pre-fabrication over framing and sheathing exterior walls in place using scaffolding became greater. Learning through problem-solving on a single project was shared within the General Contractor organization and introduced into successive projects, which was only possible because practitioners could describe what they experience as a series of activities that could be repeated regardless of the specific technical challenges they faced on new projects.

- Evolutionary Learning Capability: the assessment indicates that project teams became better at problem-solving and transferring knowledge, and that routines were better understood, which in turn increased their application, integration, effectiveness. An Xwall production system emerged and was optimized, especially on the last two projects.

\section{CONCLUSION}

The analysis of X-wall capability-building indicates that Fujimoto's theory can be useful and possibly the foundation for a comprehensive approach enabling companies and project teams to develop the capabilities they need fast enough to improve project delivery outcomes. Further retrospective studies coupled with proactive capability-building based on Fujimoto are needed. This can be a meaningful contribution to Lean Construction theory.

\footnotetext{
${ }^{6}$ Without considering scaffold, pre-fabrication was approximately $15 \%$ less expensive. Once the cost of scaffold is subtracted, pre-fabrication was much less expensive than the traditional stick-build approach. Prefabrication panel and water vapor barrier quality was far superior. Safety was greatly improved by eliminating scaffold. Interestingly because scanning was required for pre-fabrication, the team found other areas of the project where scanning could add benefits in different ways; specifically, pre-concrete-pour and post-pour scanning were experimented with and developed as a consequence of the pre-fabrication experiment.
} 